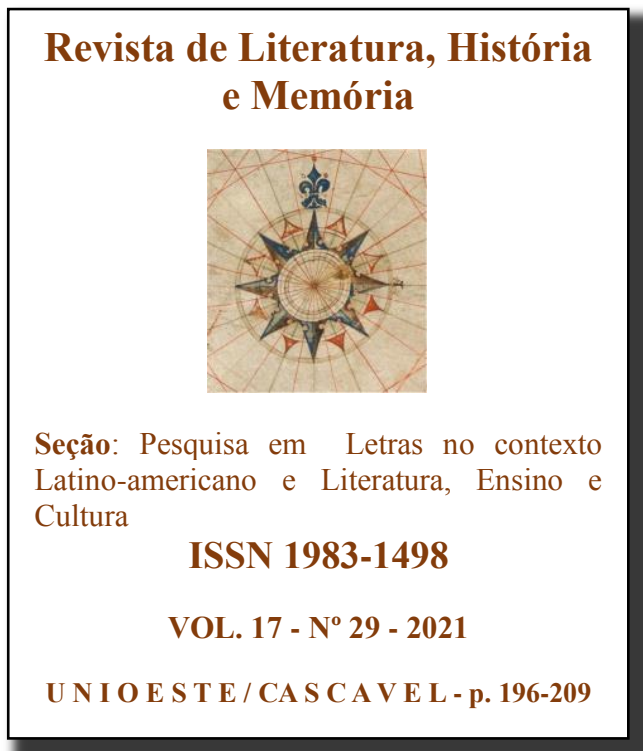

\title{
TEATRO NEGRO NO BRASIL: UMA ANÁLISE DE "SORTILÉGIO", DE ABDIAS DO NASCIMENTO
}

Black theater in Brazil: an analyze of "Sortilégio", written by Abdias do Nascimento

\author{
Marcela Gizeli Batalini ${ }^{1}$ \\ Alba Krishna Topan Feldman ${ }^{2}$
}

RESUMO: O presente trabalho tem por objetivo analisar a peça Sortilégio: mistério negro, escrita por Abdias do Nascimento em 1951, ao integrar o Teatro Experimental do Negro (TEN), no Rio de Janeiro, mas publicada apenas em 1961. Embora críticas tenham sido delineadas quanto a um viés ainda polarizado com relação as culturas apresentadas, bem como a aspectos estruturais das peças, comum nesse primeiro momento de atividades e discussões, não se pode ignorar sua importância na valorização da identidade negra, concedendo a tais indivíduos papéis centrais, como a inserção da cultura afro-brasileira em primeiro plano, o que até então não era comum no teatro brasileiro, influenciando, portanto, diversos grupos atentos a essas questões na atualidade.

PALAVRAS-CHAVE: Peça; Sortilégio; Análise.

ABSTRACT: This work aims to analyze the play theater Sortilégio: mistério negro, written by Abdias do Nascimento in 1951, when integrating the Teatro Experimental do Negro (TEN), in Rio de Janeiro, but only published in 1961. Despite the criticisms related to a bias still polarized with respect to cultures, as well as to structural aspects of the plays, common in this moment of activities and discussions, we can not ignore their importance in the valorization of the black identity, granting to these individuals central roles, like the insertion of the culture afro-brazilian in the foreground, which until then was not common in the Brazilian theater, influencing, therefore, several groups attentive to these questions nowadays.

KEYWORDS: Play theater; Sortilégio; Analyze.

\section{INTRODUÇÃO}

Ao enfocarmos a produção teatral brasileira do século XIX e ao menos metade do século $\mathrm{XX}$, verificamos a figura do negro (quando presente), não raro, vinculada a papéis inferiores, como o de servo; a partir de estereótipos negativos, relacionados à desordem, ao mal; bem como a degradação e negação de sua cultura, tão enfatizados por Miriam Mendes

\footnotetext{
${ }^{1}$ Mestre em Letras, área de concentração: Estudos Literários, pela Universidade Estadual de Maringá. Aluna regular do Doutorado em Letras da Universidade Estadual de Maringá, na linha de pesquisa: Literatura e construção de identidades.

${ }^{2}$ Doutora em Letras na Universidade Estadual Paulista "Júlio de Mesquita Filho", (UNESP), de São José do Rio Preto, e complementação na Louisville University (2009), nos Estados Unidos. Pós-Doutorado em Letras na Universidade Estadual de Londrina e em Simon Fraser University (Canadá). Professora de Língua e Literaturas de Língua Inglesa, Universidade Estadual de Maringá (Departamento de Letras Modernas/Programa de Pósgraduação em Letras).
} 
(1982) e Abdias do Nascimento (1961; 2004).

Como exemplo, poderíamos citar $O$ demônio familiar (1857), de José de Alencar, cujo personagem Pedro, elemento característico dessa sociedade: o jovem negro "doméstico", ainda que tenha bastante participação na peça, é apresentado como alguém sem escrúpulos, malicioso, que concede comicidade à obra. Nas palavras de Eduardo, representante desse mundo burguês: "a consequência de abrigarmos em nosso seio répteis venenosos; quando menos esperamos mordem o coração" (Ato II, Cena VI). Também não há preocupação, por parte do personagem, no que tange à luta pela sua situação social, agindo antes em benefício próprio, alheio ao significado efetivo de liberdade.

Em Os dois ou O inglês maquinista (1842), de Martins Pena, autor das classificadas "comédias rebaixadas", podemos observar aspectos e costumes bastante recorrentes da sociedade escravocrata brasileira, como no trecho em que Clemência ouve o barulho da louça que se quebra na cozinha, derrubada pelo cachorro, mas cujos castigos são dirigidos às negras que trabalhavam no local, pois "ouve-se dentro da bulha como se bofetadas e chicotadas" (Ato Único, Cena VI). Desse modo, embora enfoque, de modo crítico, situações vivenciadas no país, os negros possuem ainda uma presença limitada, ou seja, tais questões não ocupam o primeiro plano.

Na peça História de uma moça rica (1861), de Pinheiro Guimarães, a personagem Braúlia é esperta, ardilosa, seu objetivo é tornar-se senhora, ter melhores condições de vida, e, portanto, ocupar o lugar de Amélia, como observamos em um diálogo com o servo João, a quem ela condena a passividade: "Para você isso pode ser muito; para mim, não"/ "Quero ser senhora" (Ato II, Cena VIII). Verificamos, portanto, que, embora haja uma consciência crítica sobre sua situação, ela não luta contra o sistema, mas em prol de seus objetivos pessoais, ou seja, não há ainda um sentimento coletivo de luta pela raça, pela classe.

Mesmo em obras como $O$ dote (1907), de Artur Azevedo, conhecido primeiro pelas Operetas, um tipo de espetáculo musicado, depois pelas Revistas de Ano e considerado abolicionista, autor de $O$ escravocrata (1882), encontramos o estereótipo do escravo fiel, agora velho, chamado Pai João, bondoso e devoto ao "sinhozinho", doutor Ângelo. A quem as cantigas de cativeiro (entoadas pelo velho) faz adormecer: "Psiu! ... Tá dlumindo... Passou essa z'nóte turo em clalo.., pegou no sono agolinha memo... Zá viu? Cantiga de cativêlo semple sleve p'laguma cosa” (Ato III, Cena II), novamente não há um espírito de luta, a busca pela liberdade.

Somam-se a isso, episódios em que atores brancos são "pintados" de negro para interpretarem os protagonistas. A exemplo da peça Anjo Negro (1946), de Nelson Rodrigues, 
que não correspondeu à expectativa do mesmo, uma vez que foi utilizada a técnica de brochar um branco de negro para viver no palco o personagem Ismael.

Nesse contexto, não se pode ignorar as contribuições advindas do Teatro Experimental do Negro (TEN) no Brasil, a partir de 1944. Ainda que críticas sejam tecidas no que tange a aspectos estruturais das peças, bem como à presença inconsistente do público negro nas apresentações, devido sobretudo a fatores socioeconômicos, teve como objetivo a valorização da cultura afro-brasileira, a constituição de um teatro efetivamente negro, engajado na luta político-racial no país, influenciando inúmeros grupos teatrais na atualidade.

Frente a isso, o presente trabalho tem por objetivo desenvolver uma análise da peça Sortilégio: mistério negro, escrita por Abdias do Nascimento em 1951, quando ainda integrava o TEN, mas publicada apenas em 1961. Nosso foco concentra-se, então, na obra em si, não nos atendo a aspectos inerentes à encenação dela, e traçando, inicialmente, informações acerca do grupo, para melhor compreensão de suas produções.

\section{ALGUMAS CONSIDERAÇÕES SOBRE O TEATRO EXPERIMENTAL DO NEGRO - TEN}

As décadas de 1940 e 1950 têm como marco a busca pela "nacionalização" do teatro brasileiro, a atualização dos conteúdos, a inclusão do popular, dos conflitos e contradições sociais vivenciadas no país. Verificam-se o desenvolvimento de grupos amadores, como "Os comediantes" (1938-1947), no Rio de Janeiro; de grupos estudantis, como o "Teatro do Estudante do Brasil" (TEB), de 1938 a 1952; bem como do "Teatro Experimental do Negro" (TEN), que colaborou com o TEB já na encenação da peça Palmares, 1943, de Stella Leonardos, e, em 1947, uniu-se ao grupo "Os Comediantes" para montar a peça Terras do Sem Fim, texto adaptado de Jorge Amado. Grupos contemporâneos que compartilhavam desafios e conhecimentos.

É preciso considerar também o movimento político e literário da Negritude, organizado por escritores negros de países que foram colonizados pela França, a partir da década de 1930, tendo como objetivo a valorização da cultura negra perante as opressões colonialistas, o reconhecimento de uma identidade própria. Tal movimento, bem como a organização da revista Présence Africaine (em 1947), pelo escritor senegalês Alioune Diop, em Paris, como destaca Elisa Nascimento (2003), propiciou a grupos como o Teatro Experimental do Negro entrar em contato com reivindicações e lutas que ganhavam espaço no cenário internacional, e, mais tarde, influenciariam embates frente à independência. 
Idealizado e fundado por Abdias do Nascimento, em parceria com Maria Nascimento e Guerreiro Ramos, o TEN iniciou suas atividades em 1944, no Rio de Janeiro, com intuito de trabalhar a valorização do negro por meio da educação, da cultura e da arte. Por isso, sua primeira tarefa concentrou-se na formação educacional/crítico-reflexivo de seus participantes, recrutados entre operários, empregadas domésticas, funcionários públicos, donas de casa, dentre outros/as trabalhadores/as. Ou seja, busca-se problematizar essa sociedade que há séculos tentava esconder as práticas do racismo "com a peneira furada da 'democracia racial"”, conscientizá-los; para, então, "criar um organismo teatral aberto ao protagonismo do negro, onde ele ascendesse da condição adjetiva e folclórica para a de sujeito das histórias que representasse" (NASCIMENTO, 2004, p.211).

Foram necessários seis meses voltados às aulas e atividades práticas de atuação para que o grupo pudesse apresentar-se publicamente. Contudo, outro desafio impôs-se: a escassez de obras que refletissem efetivamente a situação existencial do negro no país, que o contemplasse enquanto indivíduo, não meramente pelas funções exercidas, ou a partir de estereótipos. Sem muitas opções, a peça Imperador Jones (1920), de Eugene O’Neill, surge como uma possibilidade, a qual o autor cede gratuitamente os direitos por meio de uma carta enviada a Abdias do Nascimento, em dezembro de 1944, de São Francisco. Nela, O’Neil relata conhecer bem as condições que ele descreve no teatro brasileiro, próximas às vivenciadas em Nova Iorque quando encenada a peça, também desejando sucesso para o Teatro Experimental do Negro (O’NEILL, 1944 apud NASCIMENTO 2004). O espetáculo estreou em maio de 1945, no Teatro Municipal do Rio de Janeiro, revelando o ator negro Aguinaldo Camargo, entretanto com uma única noite de apresentação concedida no período.

Em 1946, outro texto de Eugene O’Neill foi encenado, desta vez: Todos os filhos de Deus têm asas (All God's Chillun Got Wings - 1924), no Teatro Fênix. No fim do mesmo ano, foi montado o clássico Othello, de William Shakespeare, como parte da programação do Festival do Segundo Aniversário do TEN, no Rio de Janeiro.

A primeira peça escrita para o grupo foi em 1947, O filho pródigo, de Lúcio Cardoso, em três atos, inspirada na parábola bíblica de mesmo nome, encenada no Teatro Ginástico do Rio de Janeiro. Posteriormente, o TEN apresentou Aruanda, também em três atos, escrita por Joaquim Ribeiro. Permeada por uma atmosfera de mistério e sensualidade, traz o amor entre Rosa Mulata e o Deus Gangazuma, cujo marido é quem recebe o espírito. Há, portanto, uma interação entre as divindades e os seres humanos, uma integração com a dança, o canto, a poesia e os terreiros de candomblé. A montagem deu origem ao "Brasiliana", grupo formado por dançarinos, cantores e percussionistas, que percorreu a Europa por quase dez anos. Em 
1948, José de Morais Pinho escreveu Filhos de santo, ambientada nos subúrbios do Recife, trazendo questões inerentes ao misticismo e à exploração por religiosos do candomblé, na figura do pai de santo Roque; a paixão de um homem branco por Lindalva (a quem a mãe a princípio apoiava, por sua posição social) e a de seu amigo de infância, Josias; bem como a perseguição de trabalhadores grevistas pela polícia. Ela foi encenada em 1949, no Teatro Regina, no Rio de Janeiro.

No entanto, uma das peças mais representativas do TEN talvez seja Sortilégio: mistério negro, de Abdias do Nascimento, escrita em 1951, mas, devido à censura do período (acusada de imoral), encenada pela primeira vez em 1957, no Teatro Municipal do Rio de Janeiro. A peça expõe o conflito do protagonista frente à identidade/cultura de origem africana e a da sociedade dominante eurocêntrica, permeada por elementos do candomblé. De acordo com Elisa Nascimento (2003), foi publicada em inglês não apenas em forma de livro, editado por uma instituição de Chicago, mas também em duas antologias de literatura da diáspora africana (BRANCH, 1993; CALLALOO, 1995). Obra que constitui nosso objeto de análise no tópico a seguir.

Além dos palcos, o grupo esteve engajado na luta político-social. À época da Convenção Nacional do Negro, em 1946, foi organizada a Associação das Empregadas Domésticas, como destaca Elisa Nascimento (2003), que tinha como porta-vozes atrizes como Ruth de Souza. Dentre as reivindicações, estava o registro profissional, o direito à sindicalização e à regulamentação da profissão. Em maio de 1950, foi fundado o Conselho Nacional das Mulheres Negras, voltado à mulher e à infância, auxiliando nos direitos básicos de cidadania e educação, inclusive com cursos profissionalizantes.

Também editou o jornal Quilombo (1948-50), que discutia vários aspectos relacionados às questões raciais no Brasil, a exemplo de um "Manifesto político dos negros fluminenses aos partidos políticos", e da coluna intitulada "Fala mulher". Em 1955, promoveu a Semana do Negro, com lugar na Associação Brasileira de Imprensa, e um concurso de artes plásticas tendo como tema o Cristo Negro, com cerca de 80 trabalhos de pintura, em diferentes sentidos e técnicas (NASCIMENTO, 2003, p. 296, 306).

Contudo, o TEN teve curta duração no país, além da falta de recursos e de um espaço físico próprio, vivendo de sucessivos empréstimos de locais que eram retomados pelos donos, precisou enfrentar a censura do período, que culmina com a ditadura instalada em 1964. Perseguido por vários IPMs (Inquérito Policial Militar), instrumento de repressão, o diretor do TEN, Abdias do Nascimento, viajou em 1968 aos Estados Unidos, e o grupo teve dificuldade em manter suas atividades. 
Eles também precisaram lidar com algumas críticas. No que se refere a tais peças, objetiva-se uma atualização do conteúdo, a partir de elementos da cultura afro-brasileira, dos problemas sociais locais, do racismo latente, mas sem uma ruptura total na forma. Tal como destaca Iná Costa (2011), há ainda a utilização de um teatro convencional para examinar a problemática do negro no Brasil, fazendo com que sua trajetória enfrentasse paradoxos, embora na peça a ser estudada (Sortilégio) possamos ver alguns rompimentos se projetando, como discorreremos a seguir.

Miriam Mendes (1982) também ressalta que, apesar da preocupação em se evitar o “exótico", os estereótipos cristalizados, o TEN não conseguiu cumprir completamente uma de suas metas mais importantes: a inclusão efetiva do negro no público espectador brasileiro, não por incapacidade, mas pela situação social e econômica em que geralmente se encontrava, tornando difícil o acesso às apresentações em grandes teatros.

Todavia, as atividades do TEN realizaram uma abertura para que o negro se destacasse no cenário teatral brasileiro, principalmente no papel de ator; assim como propiciaram reflexões/debates sobre o lugar relegado a ele socialmente. Como destaca Iná Costa (2011), um projeto bastante audacioso, se pensarmos no racismo ainda mais evidente da década de 1940. Influenciando, posteriormente, inúmeros grupos teatrais voltados a tais temáticas, como: Os Crespos (2005), Capulanas: cia de arte negra (2007), o Grupo Coletivo Negro (2010), dentre outros.

\section{UMA ANÁLISE DE SORTILÉGIO: MISTÉRIO NEGRO}

A peça Sortilégio integra a antologia Dramas para negros e prólogo para brancos, composta por sete peças escritas pelo TEN, e publicada em 1961, no Rio de Janeiro. O título "sortilégio" remete à atmosfera de misticismo que permeia a obra, somada a "mistério", que, segundo Leda Martins (1995, p.104), além de evocar o culto às divindades ancestrais, aponta à modalidade teatral da idade média da Europa, os "Mistérios", que, como em Sortilégio, "evidenciava o uso híbrido de canções, coros, recursos sonoros e plásticos variados". Pelo qual a crítica situava Sortilégio num “campo mais livre”, do poético, do mistério.

Denominada drama, no que se refere à existência de uma tensão, de um conflito entre os anseios do personagem, que conduzem à ação; ou "drama lírico" pela crítica, como destaca Elisa Nascimento (2004, p. 331), apoiados, possivelmente, no conflito intra-subjetivo do sujeito/personagem; não podemos deixar de considerar também o extra-subjetivo, que possui grande espaço na peça, ou seja, as questões culturais/sociais, remetendo a traços do épico. 
Emanuel vivencia um conflito interno no que tange à identidade/cultura negra e à eurocêntrica, mas também externo, a partir do lugar relegado a ele nesta sociedade (ao indivíduo negro, à sua raça), ou melhor, de seu "não-espaço" nesse universo (sua história, mas também o coletivo).

Ao compreendermos como traços fundamentais da forma dramática a ênfase na atuação, por meio da ação dos personagens, sem a interferência de um mediador (narrador), assim como o curso linear (ROSENFELD, 1997), vemos ressignificações e rompimentos projetados na peça. As Filhas de santo podem constituir-se como uma retomada ressignificada na função do coro (no teatro clássico grego), bem como funcionar como instância narrativa: elas explicam os acontecimentos, informam sobre a vida do personagem. Do mesmo modo, não há linearidade, pelo contrário, recorre-se a flashbacks, a partir das memórias de Emanuel, das aparições de Efigênia (que não sabemos se está realmente morta) e de Margarida, bem como as falas das filhas de santo, entrecruzando fatos e vozes.

A peça inicia-se, então, com o protagonista adentrando o morro para fugir da polícia, a partir de tais intervenções, conhecemos mais detalhes. No que se refere ao enredo dramático, temos Emanuel, um negro carioca, com aproximadamente 40 anos, de origem simples e formação católica, que, em busca de melhores condições financeiras, forma-se em direito e abandona Efigênia, sua namorada negra, também de origem humilde, para casar-se com Margarida, branca e de classe média. Contudo, ao notar que ele não pertencia, de fato, a essa sociedade que tanto buscará integrar-se, que o casamento fora arranjado para manter a honra da jovem (não mais casta), e que ela, temendo que o filho nascesse negro, o abortara, tem um acesso de raiva. Como consequência, aperta seu pescoço no intuito de assustá-la, mas acaba a matando, e, portanto, esconde-se no morro. Entretanto, esse enredo dramático não se sustenta, não ocupa o primeiro plano, em nenhum momento a polícia chega, ocorre uma perseguição, nem o ideal de amor se materializa, há conciliação em algum desses aspectos, pelo contrário, são os conflitos vivenciados (intra e extra-subjetivos) que ocupam lugar principal. Passemos, portanto, à discussão da obra, buscando contemplar tais questões.

No que tange à disposição da peça, essa se inicia pela apresentação dos personagens, lembrando a presença do coro interno de tamboristas, cantores, filhas, filhos e pai de santo. Posteriormente, por meio de uma nota, o autor deixa claro que "não pretende trazer à cena a fotografia etnográfica da macumba ou do candomblé, nem a simples reprodução folclórica dos rituais negros" (NASCIMENTO, 2003, p. 161). Ou seja, busca-se superar tais rituais como mero alimento exótico, folclórico que até então eram concebidos e mostrá-los como parte do legado cultural africano no Brasil, o resgate de uma cultura, identidade. 
A seguir, informa sobre o cenário: um bosque, no alto do morro, o peji de Exu (local para culto), uma grande árvore: a gameleira sagrada, e, ao pé dessa árvore, uma enorme lança de Exu. Por entre as folhagens, o luar ilumina as três filhas de santo, agachadas ao pé da árvore, vestidas de branco, finalizando um "despacho", e antecipam a chegada do protagonista: "TODAS (juntas) - serviço bem feito. / II FILHA DE SANTO - Daqui a pouco começa a festa. Emanuel não demora” (NASCIMENTO, 1961, p. 163).

Estas conhecem a trajetória do personagem, apontam para o que representa ser negro, a necessidade de construir um lugar seu, e preconizam o seu retorno onde habitam os orixás:

II FILHA DE SANTO - Será a cor um destino?

III FILHA DE SANTO (convicta) - O destino está na cor. Ninguém foge do seu destino.

II FILHA DE SANTO - Preto quando renega a Exu...

I FILHA DE SANTO - ...Esquece os orixás... (NASCIMENTO, 1961, p. 164).

I FILHA DE SANTO (lírica) - ...e ele retornará sem memória, puro e inocente como um recém-nascido, à grande noite iluminada de Aruanda. (NASCIMENTO, 1961, p. 165).

Nessa perspectiva, é necessária e merecida sua partida, no intuito de renascer junto à religião/cultura dos seus, da qual buscou distanciar-se, objetivando integrar uma sociedade em que não era efetivamente aceito.

Em seguida, temos a descrição do segundo plano, onde surgem o Orixá e as filhas de santo, um foco de luz o segue, ele espia a ribanceira, observa, aguardando a chegada de alguém. Então, ao avistar o que esperava, esconde-se atrás das árvores. Nesse instante, surge Emanuel, ofegante, dirigindo-se à ribanceira, ele fala:

EMANUEL - Desta vez não me pegam. Não sou mais aquele estudante idiota que vocês meteram no carro forte. Aos bofetões. Preso por quê? O carro não pode regressar vazio à delegacia. Me racharam a cabeça com socos e cassetetes. [...] Mas... como foi que vim parar neste lugar? Isto aqui é perigoso. Que imprudência. A polícia costuma dar batidas nos "terreiros". Prendem tambores sagrados, filhas e pais de santo... (NASCIMENTO, 1961, p. 166).

Neste trecho, podemos observar as violências sofridas por Emanuel, oriundas do preconceito, atrelando-se a cor da pele ao universo da criminalidade, das transgressões, que o faz renegar sua identidade, distanciar-se dessa cultura. Também a perseguição às religiões de matriz africana no país, vistas como meio de exploração, a degradação de suas crenças, atreladas ao mal, ao atraso, internalizadas pelo próprio personagem: 
EMANUEL - [...] É por isso que essa negrada não vai para a frente. Tantos séculos no meio da civilização... e o que adiantou? Ainda acreditando em feitiçaria... praticando macumba... evocando deuses selvagens... (NASCIMENTO, 1961, p. 167).

A partir das falas de Emanuel, verifica-se que, embora desenvolva uma espécie de aversão à cultura e religião de matriz africana, recorra a Deus ao avistar o despacho, conhece bem suas características: sabe que fora destinada a Exu (e quem é), indica o Peji, a gameleira sagrada, onde o terreiro localiza-se, o nome dos deuses invocados (Obatalá, depois Xangô, Inhansã, Omolu, Iemanjá, e, à meia noite, Exu), enfim, vários elementos concernentes aos rituais. Ao passo que seu nome: Emanuel (do termo hebraico Immanuel, composto pelos elementos immánu, "conosco", e $E l$, "Deus"), indica sua formação cristã, e remete ao conflito vivenciado por ele:

EMANUEL (pensativo) - Imaginem, eu falando como se também acreditasse nessas bobagens. Eu, o doutor Emanuel, negro formado, que fez primeira comunhão criança. Mamãe rezava comigo... Me ensinava o catecismo... (NASCIMENTO, 1961, p. 169).

O personagem também expõe sua fuga perante o assassinato de Margarida, cuja intenção era apenas assustá-la. Contudo, tais falas são interrompidas pelo som dos atabaques, pelas palavras do Pai de Santo, dando início aos rituais, que vão ocorrer em vários momentos da peça: "No fundo do mar 'tá' de ronda.../ de ronda Iemanjá/ Quem 'tá' lá de cima de ronda.../ De ronda é Obatalá" (NASCIMENTO, 1961, p. 168), integrando-se canto, dança, gesticulações, uso de máscaras, adornos, elementos da função.

Em seguida, temos as lembranças do protagonista, bem como as falas das filhas de santo, que trazem os acontecimentos à tona. Como em um momento de desabafo, uma espécie de balanço de sua vida, ele recorda:

EMANUEL (evocando) - Naquela noite já estava noivo de Margarida. Fomos a um baile. Na volta... de madrugada, resolvemos caminhar um pouco. Subitamente ao nosso lado encostou uma camioneta da polícia: I VOZ AGRESSIVA - Um negro beijando uma branca. II VOZ AGRESSIVA - É um assalto. III VOZ AGRESSIVA - Está agredindo.

EMANUEL - Os tiras me surraram. Socos... ponta-pés. Me atiraram no carro de presos. (NASCIMENTO, 1961, p. 177).

EMANUEL - Depois da cerimônia nos beijamos. Foi aí que notei: aquele espanto nos olhos de todo mundo. Bem na minha frente, a face envergonhada de sua mãe Margarida (desanimado seus olhos procuram até se fixarem na garrafa de cachaça). Se eu experimentasse um trago de cachaça? (vai apanhá-la, recua a mão, amedrontado). Dizem que bulir em 
despacho de Exu dá azar. (pausa breve) (NASCIMENTO, 1961, p. 169).

Notamos que, se na sociedade que objetivava fazer parte, Emanuel é silenciado, não tem, efetivamente, direito à fala: "me atiraram no carro"; no morro, nos entornos do terreiro, pode falar, denunciar as atitudes preconceituosas direcionadas a ele, que não destoam, em grande medida, do cenário brasileiro contemporâneo: "a peneira furada da 'democracia racial'", denunciada por Nascimento (2004, p.211). Assim como a problemática do casamento inter-racial na década de 50, o olhar de "repudio" direcionado a ele pela família de Margarida, que representava toda essa sociedade.

A partir de tais reflexões, percebemos que o personagem adentra, cada vez mais, esse território. Primeiro, a bebida: "se eu experimentasse um trago de cachaça?” (NASCIMENTO, 1961, p. 169); depois, acende o defumador: "deixa ver o cheiro da perfumaria" (NASCIMENTO, 1961, p. 170), em cuja fumaça surge Efigênia, ao som do Ponto de Inhansã, pelo coro das filhas e filhos de santo.

Há nesse trecho acusações por parte de Emanuel a Efigênia, personagem, que junto a Margarida, corrobora para intensificar os conflitos vivenciados por ele. Para o protagonista, a ex-namorada tornara-se mero objeto nas mãos dos homens brancos: "Você já observou como os brancos olham para você? Com ar de donos? [...] Basta desejar uma negra, e pronto: dorme com ela" (NASCIMENTO, 1961, p. 173). Mais tarde, Efigênia o responde, afirmando que, abandonada por ele, apropriara-se dos meios disponíveis para melhorar sua condição, o que reforça a luta individual e não pela raça, classe, como muito se reivindica na atualidade:

EFIGÊNIA - Usei meu corpo como se usa uma chave. Você me ensinou imitar as colegas brancas. Então? Qual era a vida delas? Você sabia: vestidos elegantes... perfumes franceses... música... uísque... No princípio, oh! Como tudo isso me encantava! (NASCIMENTO, 1961, p. 180).

Ao final de sua fala, deixa-se entrever a consciência de seu distanciamento, de sua alienação: "tudo isso me encantava". Enfim, não haveria hierarquia entre os erros, ambos se afastaram de suas raízes, mas, no caso de Efigênia, não sabemos o desfecho, se, de fato, buscara retornar a essas matrizes.

Assim, como uma espécie de saudação ritual dos terreiros, ao qual Emanuel irá integrarse posteriormente, enquanto o canto sobe, a dança das Iaôs atinge o clímax, o Orixá entra, benze o negro com fumaça, tira do pescoço um colar de algas marinhas (guia sagrada de Iemanjá) e, sem tocá-lo, coloca-o no seu pescoço: 
EMANUEL - Que mironga é esta no meu pescoço? Quem está tentando me enfeitiçar? Não acredito em macumba, já disse. (pausa, reflete...) Sempre debochei dessa cangira... Mas... se for tudo verdade? Se estiver acontecendo mesmo? Afinal de contas, é o culto do meu povo. Só porque me formei vou desprezar a religião do meu sangue? Se algum Orixá estiver tratando de me livrar da cadeia dos brancos? (NASCIMENTO, 1961, p. 178).

O desprezo antes exposto pelo personagem, suas "convicções", construídas no contexto em que estava inserido, dão lugar à reflexão, aos questionamentos: "se for tudo verdade?”, a busca por sentir-se parte, encontrar-se: "meu povo", "meu sangue".

Assim, como uma tentativa de libertar-se do peso da culpa, confessa o ocorrido: "apenas discuti com Margarida. Minhas mãos tocaram de leve a garganta dela [...] foi só. E foi tudo (pesaroso) meu filho já não existia mais...” (NASCIMENTO, 1961, p.193). Também do peso de tentar fazer parte de um contexto que não incluía suas raízes, atirando ribanceira abaixo a camisa, as calças, a roupa que usava:

EMANUEL - Tomem seus troços. Com estas tapeações vocês abaixam a cabeça dos negros. Arrancam o orgulho deles. Lincham os coitados por dentro. E eles ficam domésticos... castrados... mansos... [...] Comigo se enganaram. Nada de mordaça na minha boca. Imitando vocês que nem macaco. Até hoje fingi que respeitava vocês... que acreditava em vocês. (NASCIMENTO, 1961, p. 193).

Nesse trecho podemos notar uma crítica a todo um sistema que "arrancava-os o orgulho" e os transformava em "domésticos", pacíficos, a falsa promessa de fazer "parte", anulando o sentimento de luta coletiva, tornando-os alheios ao significado efetivo de liberdade, como discutido nas peças do século XIX e início do século XX citadas na introdução, em contrapartida à postura adotada por ele. Não há aceitação, nem espécie de autoajuda de quem venceu, moralismo, ele também não é morto pela polícia, antes caminha em direção ao sacrifício, uma quebra com o enredo dramático:

(Emanuel, agora calmo e decidido, vai até a gameleira e ajoelha-se entre o despacho, abaixa a cabeça na direção do peji. [...] As filhas de santo rapidamente o envolvem e o atravessam com a lança de Exu. Ponto fúnebre de Jubiabá). (NASCIMENTO, 1961, p. 197, grifos do texto).

Como se nota, o personagem tanto caminha para o sacrifício, quanto é guiado pelos deuses, há a força da cultura que renegou, os dois agem. Leda Martins (1995) ressalta que, a partir do desenvolvimento das cenas, pode-se observar "um trajeto de auto-afirmação individual e coletivo, um ritual de passagem, uma travessia, por meio da qual o protagonista 
adquire uma dimensão metonímica, como um signo cultural alternativo" (MARTINS, 1995, p.104). Influenciado, gerido pelos deuses e pelas filhas de santo: "Eu quero ele aqui, de rastros, antes da hora grande" (NASCIMENTO, 1961, p. 164), como ordenara Exu.

Sua morte não representa, assim, um castigo divino, princípio que não se sustenta na concepção dos rituais africanos/afro-brasileiros, "ela é uma oferenda por meio da qual o personagem restabelece sua ligação com a totalidade cósmica" (MARTINS, 1995, p. 113 - 4), concretização de uma travessia.

Desse modo, podemos observar ainda um viés polarizado no que tange às culturas/ religiões apresentadas, bastante simbólico no trecho em que Emanuel despe-se de tudo o que vestia, como se uma excluísse a outra, como dois polos opostos. Concepção problematizada, posteriormente, pelos próprios estudos culturais, a compreensão de que não há como retornar a essa cultura "pura" almejada, porque ela mesma é múltipla, uma não anula a outra. Nesse contexto, podemos recuperar a metáfora do Atlântico Negro, proposta por Paul Gilroy (2001), que remete à imagem de navios em movimento entre a Europa, América, África e o Caribe, o navio como um sistema vivo, em movimento, o qual evidencia esse momento de troca entre culturas, que resultou numa espécie de renovação: o hibridismo.

Todavia, essas questões não diminuem a importância da peça, uma vez que se busca trazer para o centro sua identidade, suas raízes, por tempos deixadas à margem, inferiorizadas, ou apresentadas como mero elemento "exótico", como objeto de "entretenimento", e, portanto, dificultando a reflexão sobre sua condição social, aspectos inerentes ao preconceito racial, à discriminação vivida na sociedade brasileira.

É preciso lembrar ainda que uma nova versão de Sortilégio foi publicada por Abdias do Nascimento em 1979, durante o período em que esteve na Nigéria, na cidade de Ile-Ife (1976 - 77). Segundo o autor, Sortilégio II: mistério negro de Zumbi redivivo "obedece à mesma estrutura da peça anterior, da qual é apenas uma versão atualizada", intensificando-se "o engajamento do mistério com suas raízes africanas, assim como o resgate da história, atualizando-a", a exemplo da inserção da figura de Zumbi e sua luta pela libertação dos povos negro-africanos (NASCIMENTO, 1979, p. 14). Uma possível menção também à Arena conta Zumbi, musical escrito por Gianfrancesco Guarnieri e Augusto Boal, em 1965, com estreia no Teatro Arena em maio do mesmo ano, assinalando a busca pela recuperação e valorização da cultura africana, de suas raízes no cenário brasileiro.

Portanto, tratando-se de uma atualização da obra, e levando-se em conta que na década de 1970 o teatro épico já está em crise no Brasil, justifica-se nossa seleção pela primeira peça, em que o momento que se insere é bastante efetivo. 


\section{CONSIDERAÇÕES FINAIS}

Ao enfocarmos a peça Sortilégio, notamos que, embora classificada como drama, ou drama lírico pela crítica, algumas ressignificações ou rupturas vão se delineando, a exemplo das filhas de santo que podem ser consideradas um resgate ressignificado da função do coro (no teatro clássico grego), ou instância narrativa; a não-linearidade da mesma, permeada por lembranças do protagonista, as aparições de Efigênia e Margarida, as falas das filhas de santo, entrecruzando fatos e vozes; o lugar central concedido aos conflitos vivenciados (intra e extrasubjetivos) por Emanuel, em contrapartida ao enredo dramático. Ou seja, o personagem vive um conflito interno entre as culturas/religiões de origem africana e eurocêntrica, as particularidades de sua história, mas também externo, no que tange à discriminação, aos problemas enfrentados em um país que difunde o mito da democracia racial.

Assim, ainda que possamos verificar um viés polarizado no que tange às culturas, presente nesse primeiro momento de discussões e estudos, busca-se colocar tais questões em primeiro plano, a inserção da cultura/religião de matriz africana não como elemento folclórico, exótico, comumente apresentado até então, mas como parte e recuperação de uma identidade, dessas raízes no Brasil.

Logo, não se podem deixar de lado as contribuições oriundas desse "experimento" na década de 1950, principalmente se pensarmos no racismo ainda mais evidente, bem como na censura do período, que resulta na ditadura. Lançando atores negros como protagonistas em um espaço que relegava a eles, quase sempre, papéis inferiores, ou eram substituídos por atores brancos pintados de negro, assim como diretores e autores, um marco para o cenário teatral brasileiro, bem como à reflexão/discussão propiciada sobre sua condição, os desdobramentos na esfera social.

\section{REFERÊNCIAS BIBLIOGRÁFICAS}

ALENCAR, J. O demônio familiar. In: Obra completa. Rio de Janeiro, José Aguilar, 1960. v. IV.

AZEVEDO, A. O dote. Rio de Janeiro: Livraria Luso-Brasileira, M. Piedade \& C., 1907.

CARDOSO, L. O filho pródigo. In: NASCIMENTO, A. (Org.). Dramas para negros e prólogo para brancos. Rio de Janeiro: TEN, 1961. p. 29-72.

COSTA, I. C. Algumas reflexões da professora Dra. Iná Camargo Costa. 14 de julho de 2011. Blog Coletivo Negro. Disponível em: http://coletivonegro.com.br/blog/algumas-reflexoes-da- 
professora-dra-ina-camargo-costa-na-ocasiao-da-pre-estreia-ocorrida-dia-14-de-julho-de2011-do-espetaculo-do-coletivo-negro-movimento-numero-1-o-silencio-de-depois/ Acesso em: 15 mar. 2018.

GILROY, P. O Atlântico Negro. São Paulo: Editora 34, 2001. p. 33-100.

GUIMARÃeS, F. P. História de uma moça rica. In: GUIMARÃes NETO, P. Pinheiro Guimarães, na esfera do pensamento. Rio de Janeiro, s. ed., 1937.

MARTINS, L. M. A cena em sombras. São Paulo: Editora Perspectiva, 1995.

MARTINS PENA, L. C. Os dous ou O inglês maquinista. In: Obra completa. Rio de Janeiro, MEC/INL, 1956. Ed. Crítica.

MENDES, M. G. A personagem negra no teatro brasileiro. São Paulo: Ática, 1982.

NASCIMENTO, A. Sortilégio: Mistério Negro. In: prólogo para brancos. Rio de Janeiro: TEN, 1961. p.159-197. (Org.). Dramas para negros e

NASCIMENTO, A. Sortilégio II: mistério negro de Zumbi redivivo. Rio de janeiro: Paz e Terra, 1979. p. 13-16.

NASCIMENTO, A. Teatro Experimental do Negro: trajetória e reflexões. Estudos Avançados, São Paulo, v.18, n.50, p.209-224, 2004.

Disponível em: $\quad$ http://www.scielo.br/scielo.php?script=sci arttext\&pid=S0103$\underline{40142004000100019}$. Acesso em: 10 mar. 2018.

NASCIMENTO, E. L. O Sortilégio da cor: identidade, raça e gênero no Brasil. São Paulo: Selo Negro Edições, 2003.

PINHO, J. M. Filhos de santo. In: NASCIMENTO, A. (Org.). Dramas para negros e prólogo para brancos. Rio de Janeiro: TEN, 1961. p. 233-286.

RIBEIRO, J. Aruanda. In: NASCIMENTO, A. (Org.). Dramas para negros e prólogo para brancos. Rio de Janeiro: TEN, 1961. p. 287-307.

ROSENFELD, A. O teatro épico. 3. ed. São Paulo: Perspectiva, 1997. 